\title{
P-168
}

\section{Evaluation of Tribal Medicinal Plants of Ramghat Region for their Antidiabetic Potential In Alloxan Induced Diabetic Rats}

\author{
Sneha Keerthi N.R ${ }^{1, *}$, Rajarajeshwari $\mathrm{N}^{1}$, Namita $\mathrm{N}^{1}$, Shyam $\mathrm{K}^{1}$, Parixit $\mathrm{B}^{2}$ and Ganapaty $\mathrm{S}^{2}$ \\ ${ }^{1}$ Department of Pharmacognosy and Phytochemistry Visveswarapura Institute of Pharmaceutical Sciences, BSK-2 ${ }^{\text {nd }}$ \\ stage, Bangalore- 560070, India; ${ }^{2}$ Department of Pharmacognosy and Phytochemistry, University College of \\ Pharmaceutical sciences, Andhra University,Visakhapatnam- 530003, India; E-mail: sneha.nr@gmail.com
}

This study presents the rich resource of medicinal plants used by the tribes of Ramghat region of Western Ghats (Maharastra, India) against diabetes. It was aimed to identify and screen the important species used in the management of Diabeties and these plants create a basis for phytochemical evaluation which can lead to the discovery of biologically active compounds. In the present study, Pet-ether, Chloroform, Ethyl acetate and Ethanol extracts of fruits of Bredilia retusa, Habenaria rarifolia, Syzigium hemisphericum, Hydnocarpus pentandra were comparatively evaluated for their blood glucose lowering and hyperlipidaemic activity. The ethyl acetate and ethanolic extract showed significant activity in acute study as compare to diabetic control, but none of the extract showed significant results in prolonged study. The experiment also confirmed that ethyl acetate and ethanolic extracts significantly reduced the elevated total cholesterol, triglyceride level, SGOT, SGPT, ALD and Urea level. Our data suggests a significant antidiabetic and hyperlipidaemic effects of all the fruit extracts in alloxan diabetic rats.

Keywords: Anti-diabiabetic, Bredilia retusa, Habenaria rarifolia, Syzigium hemisphericum, Hydnocarpus pentandra. 